\title{
Evaluation of Serum Antioxidants during Adjuvant Chemotherapy of Breast Cancer- A Prospective Observational Study
}

\section{Kadam Charushila $\mathbf{Y}^{*}$ and Abhang Subodhini $A$}

Department of Biochemistry, Byramjee Jeejeebhoy government medical college, Pune, India

*Corresponding author: Kadam Charushila Y, Department of Biochemistry, Byramjee Jeejeebhoy government medical college, Pune, India, E-mail: tillu299@yahoo.com

Rec date: Jan-27-2015; Acc date: Apr-21-2015; Pub date: Apr-23-2015

Copyright: () 2015 Kadam CY, et al. This is an open-access article distributed under the terms of the Creative Commons Attribution License, which permits unrestricted use, distribution, and reproduction in any medium, provided the original author and source are credited.

\begin{abstract}
Background: The enzymatic and non-enzymatic antioxidant defense systems of the cell prevent oxidant mediated damage to different biomolecules by neutralizing free radicals generated during anticancer drug metabolism. Reduced glutathione $(\mathrm{GSH})$ and glutathione dependent enzymes such as glutathione peroxidase (GP $\mathrm{P}_{\mathrm{x}}$ and glutathione-s-transferase (GST) are the key determinants of cellular response to oxidative stress. The objective of this study was to evaluate changes in serum levels of these antioxidants after first cycle of adjuvant chemotherapy in breast cancer patients.
\end{abstract}

Material and Methods: Histopathologically proven 60 breast cancer patients were included in the present study. The blood samples were taken after surgery before chemotherapy and after 3 weeks of administration of first cycle of chemotherapy. 30 healthy female controls were selected for comparison. Serum GSH and GST were estimated by spectrophotometric methods and serum $\mathrm{GP}_{\mathrm{x}}$ was estimated by ELISA.

Results: The serum levels of GSH, GST and $\mathrm{GP}_{\mathrm{x}}$ were significantly decreased $(\mathrm{P}<0.0001)$ after first cycle of adjuvant chemotherapy in breast cancer patients as compare to levels before chemotherapy. A significant positive

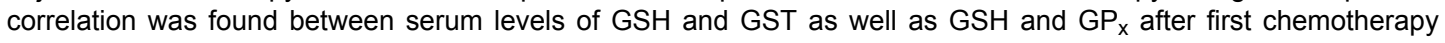
cycle.

Conclusion: Our data suggests that administration of chemotherapeutic drugs causes depletion of reduced glutathione and glutathione-dependent enzymatic antioxidants such as GST and $\mathrm{GP}_{\mathrm{x}}$, which may be due to higher oxidative stress after chemotherapy.

Keywords:

Breast cancer; Adjuvant chemotherapy; Reduced glutathione; Glutathione-s-transferase; Glutathione peroxidase; Antioxidants

\section{Introduction}

Breast cancer is one of the most common types of cancer in women and is second leading cause of cancer-related deaths in women worldwide $[1,2]$. The chance of developing invasive breast cancer at some time in women's life is a little less than 1 in 8 . Breast cancer accounts for $25 \%$ to $32 \%$ of all female cancers in India. According to most recent estimates of IARC (International Agency for Research on Cancer, WHO), about 44,937 new cases of invasive breast cancer were diagnosed and about 70,218 women were died due to the disease in India $[3,4]$.

The etiology of breast cancer is multifactorial. Significant risk factors includes early age at menarche, late age at menopause, family history, use of oral contraceptives, mutations in BRCA 1 and BRCA 2 etc $[5,6]$. The main presenting features in women with symptomatic breast cancer include a lump in the breast, nipple change or discharge and skin contour changes. Definitive diagnosis is done by biopsy and histopathology. The treatment of choice for breast cancer is surgical intervention with chemotherapy, radiotherapy and anti-hormonal therapy either in the neoadjuvant and/or adjuvant setting depending on stage of disease [7].

Adjuvant chemotherapy is a standard systemic treatment for invasive breast cancer after surgical removal of tumor [2]. Cytotoxic chemotherapy drugs kill cancer cells predominantly by triggering apoptosis in them. Several studies have shown that antineoplastic drugs used in treatment of cancer eliminate tumor cells by inducing apoptosis in them and this, in part at least, is done by generating reactive oxygen species in them [8-10].

The enzymatic and non-enzymatic antioxidant defense systems of the cell prevent oxidant mediated damage to different biomolecules such as lipids, protein and DNA by neutralizing free radicals $[11,12]$. However, these antioxidants may inhibit apoptosis in cancerous cells induced by oxidative stress following chemotherapy by scavenging free radicals and may exert antiapoptotic and cancer promoting effects in cancer patients $[13,14]$. Reduced glutathione (GSH) and glutathione dependent enzymes such as glutathione peroxidase $\left(\mathrm{GP}_{\mathrm{x}}\right)$ and glutathione-s-transferase (GST) are the key determinants of cellular response to oxidative stress [15]. Glutathione (GSH) is ubiquitous, 
Citation: Charushila YK and Subodhini AA (2015) Evaluation of Serum Antioxidants during Adjuvant Chemotherapy of Breast Cancer- A Prospective Observational Study. Biochem Anal Biochem 4: 171. doi:10.4172/2161-1009.1000171

Page 2 of 6

most abundant, low molecular weight thiol-containing tripeptide in cells [16]. GSH effectively scavenges free radicals and other reactive oxygen species (e.g. hydroxyl radical, peroxynitrite and $\mathrm{H}_{2} \mathrm{O}_{2}$ ) directly and indirectly through enzymatic reactions [17]. In addition, GSH is involved in other biological functions including its role in maintaining body homeostasis and protecting cells against toxicants, DNAdamaging agents and carcinogens of either exogenous or endogenous source [18]. Glutathione-s-transferases (GSTs) are an enzyme superfamily involved in the phase-II metabolism. GSTs catalyze the conjugation of glutathione to electrophilic species resulting in hydrophilic species that are more readily excreted. GSTs play an important role in drug metabolism including many cancer therapeutic agents [19]. It has been known that GSTs can reduce lipid hydroperoxides through their Se-independent glutathione peroxidase activity and that these enzymes can also detoxify lipid peroxidation end products such as 4-hydroxynonenal [20]. GST has recently been implicated in protection against apoptosis [14]. Glutathione peroxidase $(\mathrm{GPx})$ is a key enzyme responsible for detoxification of cellular hydrogen peroxide using GSH; it exists in two forms- selenium dependent and selenium independent. The selenium-dependent $\mathrm{GP}_{\mathrm{x}}$ both detoxifies $\mathrm{H}_{2} \mathrm{O}_{2}$ and converts lipid hydroperoxides to non-toxic alcohols, whereas the selenium-independent enzyme is responsible only for metabolizing lipid peroxides [21-23].
The measurement of reduced glutathione in tissues and body fluids is used as an index of the oxidative stress that occurs under different pathological conditions e.g. cancer [24]. Several studies have shown that the serum levels of GSH were decreased in patients with prostate cancer and breast cancer as compared to controls which may be due to the response of increased reactive oxygen metabolite production [24-27]. However, some studies have reported increased serum levels of GSH in breast cancer patients as compared to controls [6]. In addition to this, GSTs have been reported to accumulate in various human cancer tissues [28-30]. The GST (Pi) is present at high levels in many solid tumors particularly ovarian, small cell lung, breast, liver, oesophagus, stomach, colon and pancreas [28-30]. The elevated serum levels of GST have been reported previously in breast, prostate, colon and oesophagus cancer $[6,26,30]$. However, some reports have shown decreased levels of GST in patients with breast cancer [31-33]. Similarly, the higher levels of $\mathrm{GP}_{\mathrm{x}}$ have been reported in patients with benign and malignant breast cancer as well as in patients with transitional cell carcinoma bladder [6,15,22-24,34]. However, some studies have reported decreased levels of $\mathrm{GP}_{\mathrm{x}}$ in breast, gastric, colorectal and prostate cancer $[26,35]$. Thus, available data on serum levels of GSH, GP ${ }_{x}$ as well as GST is contradictory. Furthermore, the serum levels of these antioxidants are very less studied in breast cancer patients before and after adjuvant chemotherapy.

\begin{tabular}{|c|c|}
\hline Parameter & Number \\
\hline \multicolumn{2}{|l|}{ Age } \\
\hline Range & $30-75$ years \\
\hline \multicolumn{2}{|l|}{ Diagnosis } \\
\hline Invasive ductal carcinoma & 47 \\
\hline Invasive lobular carcinoma & 13 \\
\hline \multicolumn{2}{|l|}{ Pathological TNM stage } \\
\hline Stage II & 30 \\
\hline Stage III & 30 \\
\hline \multicolumn{2}{|l|}{ Receptor status } \\
\hline $\mathrm{ER}+$ & 46 \\
\hline $\mathrm{PR}+$ & 41 \\
\hline HER2/neu + & 36 \\
\hline \multicolumn{2}{|l|}{ Menopausal status } \\
\hline Premenopausal & 21 \\
\hline Postmenopausal & 39 \\
\hline \multicolumn{2}{|l|}{ Surgery } \\
\hline Breast conserving surgery (BCS) & 19 \\
\hline Modified radical mastcetomy (MRM) & 41 \\
\hline
\end{tabular}

Table 1: Clinicopathologic characteristics of 60 breast cancer patients.

Therefore, considering paucity in the studies on serum levels of these antioxidants in breast cancer patients after adjuvant chemotherapy, we evaluated their levels in serum before and after adjuvant chemotherapy. 


\section{Material and Methods}

The present study was prospective observational study. Histopathologically proven 60 female breast cancer patients with invasive ductal/lobular carcinoma with stage II (30 patients) and stage III (30 patients) as classified TNM system were included in the present study. The patients were aged between 30 and 75 years. 30 healthy and age matched female controls were selected for comparison. Clinicopathological characteristics of patients are given in Table 1.

The study was approved by institutional ethical committee (Reference number: BJMC/IEC/Pharmac/D 1210137-39). After obtaining prior written consent, $5 \mathrm{ml}$ of venous blood was drawn under aseptic precaution after surgery before chemotherapy and 3 weeks after administration of first cycle of 5-flurouracil, epirubicin, cyclophosphamide (FEC)/Adriamycin, cyclophosphamide (AC)/ paclitaxel (standard dose) chemotherapy. The serum was separated and stored at $-80^{\circ} \mathrm{C}$ until analysis.

To avoid false positive results, care was taken to exclude patients with systemic disorders, infectious diseases, allergic diseases, autoimmune diseases, other malignancies and radiation treated patients.

The required chemicals- reduced glutathione, 1-chloro-4dinitrobenzene (CDNB) and 5-5'-Dithiobis, 2-nitrobenzoic acid were purchased from Alfa Aesar, South Korea. The serum level of $\mathrm{GP}_{\mathrm{x}}$ was determined by ELISA using ELISA kit (Cayman chemical company, USA).

\section{Measurement of reduced glutathione (GSH)}

Serum reduced glutathione was measured by method of Moron et al [36]. $0.1 \mathrm{ml}$ of serum was deproteinized by $3 \mathrm{ml}$ of $5 \%$ TCA. After mixing, tubes were kept for $5 \mathrm{~min}$ at room temperature and then centrifuged. To $1 \mathrm{ml}$ of supernatant $4 \mathrm{ml}$ of $0.3 \mathrm{M} \mathrm{Na} \mathrm{HPO}_{4}$ (pH: 8.0) and $0.5 \mathrm{ml}$ of $0.6 \mathrm{mM}$ DTNB was added. The contents were mixed by vortexing and absorbance of yellow color produced was recorded within $10 \mathrm{~min}$ at $412 \mathrm{~nm}$. The concentration of GSH from serum was calculated by use of standard curve of GSH. The values were expressed as $\mathrm{mg} / \mathrm{dl}$.

\section{Measurement of glutathione-s-transferase (GST)}

Serum GST was estimated by CDNB method [37]. GST was estimated in $1 \mathrm{ml}$ of incubation mixture containing $850 \mu \mathrm{l}$ of $0.1 \mathrm{M}$ phosphate buffer of $\mathrm{pH} 6.5$ and $50 \mu \mathrm{l}$ of $20 \mathrm{mM}$ CDNB reagent, preincubated at $37^{\circ} \mathrm{C}$ for $10 \mathrm{~min}$. Reaction was started by adding $50 \mu \mathrm{l}$ of $20 \mathrm{mM} \mathrm{GSH}$ and $50 \mu \mathrm{l}$ of serum. Reaction was followed at $1 \mathrm{~min}$ interval for $5 \mathrm{~min}$ by measuring absorption at $340 \mathrm{~nm}$. The blank was run by adding deionized water instead of serum. Then change in $\mathrm{OD} / \mathrm{min}$ was calculated. Estimation of GST was done by using the molar extinction coefficient $\left(9.6 \mathrm{mM}^{-1} \mathrm{~cm}^{-1}\right)$ of GST. GST values were expressed as IU/L.

\section{Measurement of glutathione peroxidase $\left(\mathrm{GP}_{\mathrm{x}}\right)$}

The measurement of serum glutathione peroxidase was done by ELISA according to instructions of manufacturer (Cayman Chemical Company, USA) [38]. Briefly, $100 \mu \mathrm{l}$ of assay buffer, $50 \mu \mathrm{l}$ of cosubstrate mixture and $20 \mu \mathrm{l}$ of sample was added to sample wells. For non-enzymatic well $20 \mu \mathrm{l}$ of distilled water and for control well $20 \mu \mathrm{l}$ of $\mathrm{GP}_{\mathrm{x}}$ control were added instead of serum sample. The reaction was started by adding $20 \mu \mathrm{l}$ of cumene hydroperoxide to all the wells being used. Plate was shaken carefully for few seconds to mix. The absorbance was read once every minute at $340 \mathrm{~nm}$ using a plate reader to obtain at least 5 time points. The change in absorbance per minute was determined $(\triangle \mathrm{A} 340)$. The $\mathrm{GP}_{\mathrm{x}}$ values were expressed in terms of $\mathrm{nmol} / \mathrm{min} / \mathrm{ml}$. (CV: intra-assay $5.7 \%$, inter-assay $7.2 \%$ ).

\section{Statistical analysis}

The data for biochemical analysis was expressed as Mean \pm SD. The statistical significance of the results was analyzed by using one way ANOVA and student's $t$ test. Value of $\mathrm{P}<0.05$ was considered statistically significant. Bivariate correlation analysis was used for determining correlations between measured parameters before and after chemotherapy.

\section{Results}

Table 2 shows the mean serum levels of reduced glutathione, glutathione-s-transferase and glutathione peroxidase in healthy controls and stage II as well as stage III breast cancer patients before and after adjuvant chemotherapy (FEC/AC/PC). The serum levels of reduced glutathione were significantly lower in post-operative breast cancer patients before chemotherapy in stage II $(\mathrm{P}=0.0004)$ as well as stage III $(\mathrm{P}<0.0001)$ of the disease as compare to levels in healthy controls. Further significant decrease in the levels of GSH was observed in stage II as well as stage III breast cancer patients after 3 weeks of receiving first cycle of adjuvant chemotherapy as compare to levels before chemotherapy $(\mathrm{P}<0.0001)$ and levels in healthy controls $(\mathrm{P}<0.0001)$. The serum levels of glutathione-s-transferase and glutathione peroxidase were significantly higher in post-operative stage II $(\mathrm{P}<0.0001)$ as well as stage III $(\mathrm{P}<0.0001)$ breast cancer patients before chemotherapy as compare to levels in healthy controls. After 3 weeks of administration of first cycle of chemotherapy, we found a significant decrease in the serum levels of glutathione-stransferase and glutathione peroxidase in stage II as well as stage III of the disease as compare to levels before chemotherapy $(\mathrm{P}<0.0001)$ but the values were still significantly higher as compare to levels in healthy controls $(\mathrm{P}<0.0001)$. A significant inverse correlation was observed between serum GSH and GST as well as serum GSH and GP $\mathrm{P}_{\mathrm{x}}$ in postoperative breast cancer patients before chemotherapy. However, a significant positive correlation was found between serum GSH and GST as well as serum GSH and $\mathrm{GP}_{\mathrm{x}}$ after first cycle of chemotherapy (Table 3).

\section{Discussion}

In the present study, we evaluated the serum levels of antioxidants such as reduced glutathione, glutathione-s-transferase and glutathione peroxidase in post-operative breast cancer patients undergoing first cycle of adjuvant chemotherapy (FEC/AC/PC).

Cytotoxic drugs have been known to produce highly reactive free radicals that act as common mediators of apoptosis during chemotherapy treatment of cancer [8-10,39]. The oxidative stress is the condition of overproduction of reactive free radicals or the depletion of antioxidants [40]. The generation of free radicals is controlled by large number of antioxidant systems of body. Reduced glutathione is one of the principle intracellular antioxidants. The glutathione and glutathione dependent enzymes directly scavenges free radicals and protects cells from oxidative insults. However, this 
Citation: Charushila YK and Subodhini AA (2015) Evaluation of Serum Antioxidants during Adjuvant Chemotherapy of Breast Cancer- A

Page 4 of 6

may cause apoptosis resistance in cancerous cells following

chemotherapy [11].

\begin{tabular}{|c|c|c|c|c|}
\hline Subjects & No. of cases & GSH (mg/dl) & GST (IU/L) & $\mathrm{GPx}(\mathrm{nmol} / \mathrm{min} / \mathrm{ml})$ \\
\hline Healthy controls & 30 & $3.96 \pm 1.18$ & $1.81 \pm 1.21$ & $24.22 \pm 3.53$ \\
\hline \multicolumn{5}{|l|}{ Breast cancer patients } \\
\hline Stage II before chemotherapy & 30 & $2.84 \pm 0.42 \mathrm{e}$ & $12.58 \pm 3.90 \mathrm{a}$ & $51.79 \pm 8.55 a$ \\
\hline Stage II after first cycle of chemotherapy & 30 & $1.89 \pm 0.40 \mathrm{ab}$ & $5.33 \pm 1.54 a b$ & $36.53 \pm 5.62 \mathrm{ab}$ \\
\hline Stage III before chemotherapy & 30 & $2.33 \pm 0.82 \mathrm{ab}$ & $13.01 \pm 3.79 a b$ & $69.11 \pm 16.50 \mathrm{ab}$ \\
\hline Stage III after first cycle chemotherapy & 30 & $1.79 \pm 0.53 \mathrm{ac}$ & $5.96 \pm 1.38 \mathrm{ac}$ & $50.31 \pm 13.07 \mathrm{ac}$ \\
\hline \multicolumn{5}{|c|}{$\begin{array}{l}\text { The data was expressed as Mean } \pm \text { SD. } \\
\text { a } P<0.0001 \text { Significant when compared to healthy controls. } \\
\text { e } P=0.0004 \text { Significant when compared to healthy controls. } \\
\text { b } P<0.0001 \text { Significant when compared to stage II breast cancer patients before chemotherapy. } \\
\text { c } P<0.0001 \text { Significant when compared to stage III breast cancer patients before chemotherapy. }\end{array}$} \\
\hline
\end{tabular}

Table 2: Depict serum levels of reduced glutathione (GSH), glutathione-s-transferase (GST) and glutathione peroxidase (GPx) in healthy controls and post-operative breast cancer patients before and after chemotherapy.

\begin{tabular}{|l|l|l|}
\hline Parameters & $\begin{array}{l}\text { After first chemotherapy cycle in stage II of } \\
\text { disease. }\end{array}$ & $\begin{array}{l}\text { After first chemotherapy cycle in stage III of } \\
\text { disease. }\end{array}$ \\
\hline GSH/GST & $r=+0.86$ & $r=+0.89$ \\
\hline GSH/GPX & $r=+0.89$ & $r=+0.94$ \\
\hline
\end{tabular}

Table 3: Correlation analysis of measured parameters after first chemotherapy cycle.

In the present study, we have observed significantly lower levels of reduced glutathione in post-operative breast cancer patients before chemotherapy in stage II $(\mathrm{P}=0.0004)$ as well as stage III $(\mathrm{P}<0.0001)$ of the disease as compare to levels in healthy controls. The decreased level of reduced glutathione after surgery has been reported in patients with gastric cancer by Czeczot et al. [41] as well as in patients with breast cancer (stage II) in our previous study [2]. However, in contrast to our finding, elevated level of GSH in breast cancer patients and non-significant decrease in the levels after 3 weeks of mastectomy have also been reported [6,42]. The depletion of reduced glutathione is an index of oxidative stress. The higher level of nitric oxide, which may increase production of peroxynitrite and, further oxidation of GSH or increased utilization of GSH for detoxification of lipid hydroperoxides, formed due to high oxidative stress in post-operative breast cancer patients, as described in our previous report [2], might be responsible for this depletion of GSH. Further, significant decrease in the serum level of GSH was observed in stage II as well as stage III of disease after first cycle of chemotherapy as compare to levels before chemotherapy $(\mathrm{P}<0.0001)$ and levels in healthy controls $(\mathrm{P}<0.0001)$. Our finding is in agreement with previous study reports $[8,10]$. The metabolism of antineoplastic drugs produces highly reactive electrophiles and decrease in the levels of GSH after chemotherapy indicates aggravation of oxidative stress which was possibly due to electrophilic burden on cells [13].

Reduced glutathione besides its role as scavenger of free radicals also acts in association with the detoxification enzymes glutathione peroxidase $\left(\mathrm{GP}_{\mathrm{x}}\right)$ and glutathione-s-transferase (GST). These enzymes protect cell from noxious substances by catalyzing conjugation reactions with reduced glutathione and prevents damage caused by reactive oxygen species by reducing hydrogen peroxide, lipid and phospholipid hydroperoxides [14,23]. This antioxidant function of reduced glutathione along with its associated enzymes however, may provide protection against oxidative stress mediated apoptosis [43]. The levels of GST and $\mathrm{GP}_{\mathrm{x}}$ in serum were found to be elevated in most of the human cancers studied $[23,37,43]$. The post-operative higher values of GST were reported in patients with breast cancer and cancer of digestive tract $[44,45]$. In this study, we found significantly higher values of serum GST and $\mathrm{GP}_{\mathrm{x}}$ in stage II $(\mathrm{P}<0.0001)$ as well as stage III $(\mathrm{P}<0.0001)$ post-operative breast cancer patients before chemotherapy as compare to levels in healthy controls. Our finding is in accordance with these previous study reports $[44,45]$. The higher values were observed post-operatively might be because normalization of GST [44] and $\mathrm{GP}_{\mathrm{x}}$ levels after surgery may take about a month. Further, we found significant decrease in the serum levels of GST as well as $\mathrm{GP}_{\mathrm{x}}$ after first cycle of adjuvant chemotherapy in stage II $(\mathrm{P}<0.0001)$ as well as stage III $(\mathrm{P}<0.0001)$ of the disease as compare to levels before chemotherapy, however, levels of both these enzymes were significantly higher in stage II $(\mathrm{P}<0.0001)$ as well as stage III $(\mathrm{P}<0.0001)$ breast cancer patients as compare to levels in healthy controls. Similar findings were reported by Chakraborty et al. [13]. A significant positive correlation was observed between serum levels of GSH and GST as well as GSH and $\mathrm{GP}_{\mathrm{x}}$ after first cycle of chemotherapy. GST and $\mathrm{GP}_{\mathrm{x}}$ may utilize GSH in detoxification of highly reactive electrophiles produced during cytotoxic action of chemotherapy drugs [13]. The decreased levels of both these enzymes 
observed in the present study may be related with decrease in GSH after chemotherapy.

\section{Conclusion}

Our data suggests that administration of chemotherapeutic drugs (FEC/AC/PC) causes depletion of serum reduced glutathione and glutathione-dependent enzymatic antioxidants such as GST and GP which may be due to higher oxidative stress after chemotherapy. However, the present study reports the effect of first chemotherapy cycle. Further follow-up with large study group is needed to establish the association between glutathione associated antioxidants and cancer chemotherapy.

\section{References}

1. GÃnenÃ A, Erten D, Aslan S, Akinci M, SimÅŸek B, et al. (2006) Lipid peroxidation and antioxidant status in blood and tissue of malignant breast tumor and benign breast disease. Cell Biol Int 30: 376-380.

2. Kadam CY, Abhang SA (2013) Evaluation of serum levels of reduced glutathione, glutathione-s-transferase and nitric oxide in breast cancer patients undergoing adjuvant chemotherapy. Int J Cur Res Rev 5: 51-57.

3. www.cancerresearch.purdue.edu

4. www.breastcancerindia.net

5. Badid N, Ahmed FZ, Merzouk H, Belbraouet S, Mokhtari N, et al. (2010) Oxidant/antioxidant status, lipids and hormonal profile in overweight women with breast cancer. Pathol Oncol Res 16: 159-167.

6. Rajneesh CP, Manimaran A, Sasikala KR, Adaikappan P (2008) Lipid peroxidation and antioxidant status in patients with breast cancer. Singapore Med J 49: 640-643.

7. Duffy MJ, Esteva FJ, Harbeck N, Molina R, Hayes DF (2008) National academy of clinical biochemistry guidelines for the use of tumor markers in breast cancer. NACB: Practice guidelines and recommendations for use of tumor markers in the clinic. Breast cancer 58: 1-26.

8. Panis C, Herrera AC, Victorino VJ, Campos FC, Freitas LF, et al. (2012) Oxidative stress and hematological profiles of advanced breast cancer patients subjected to paclitaxel or doxorubicin chemotherapy. Breast Cancer Res Treat 133: 89-97.

9. Conklin KA (2004) Cancer chemotherapy and antioxidants. J Nutr 134: 3201S-3204S.

10. Kasapovic J, Pejic S, Stojiljkovic V, Todorovic A, Radosevic-Jelic L et al. (2010) Antioxidant status and lipid peroxidation in the blood of breast cancer patients of different ages after chemotherapy with 5-fluorouracil, doxorubicin and Cyclophosphamide. Clin. Biochem 43: 1287-1293.

11. Zeisel SH (2004) Antioxidants suppress apoptosis. J Nutr 134: 3179S-3180S.

12. Jonas CR, Puckett AB, Jones DP, Griffith DP, Szeszycki EE, et al. (2000) Plasma antioxidant status after high-dose chemotherapy: a randomized trial of parenteral nutrition in bone marrow transplantation patients. Am J Clin Nutr 72: 181-189.

13. Chakraborty P, Ugir HSK, Murmu N, Das JK, Pal S, et al. (2009) Modulation of Cyclophosphamide -induced cellular toxicity by diphenylmethyl selenocyanate in vivo, an enzymatic study. J. Cancer Molecules 4: 183-189.

14. Huang J, Tan PH, Thiyagarajan J, Bay BH (2003) Prognostic significance of glutathione S-transferase-pi in invasive breast cancer. Mod Pathol 16: 558-565.

15. Polat MF, Taysi S, Gul M, Cikman O, Yilmaz I, et al. (2002) Oxidant/ antioxidant status in blood of patients with malignant breast tumour and benign breast disease. Cell Biochem Funct 20: 327-331.

16. Pastore A, Federici G, Bertini E, Piemonte F (2003) Analysis of glutathione: implication in redox and detoxification. Clin Chim Acta 333: 19-39.
17. Wu G, Fang YZ, Yang S, Lupton JR, Turner ND (2004) Glutathione metabolism and its implications for health. J Nutr 134: 489-492.

18. De Flora S, Izzotti A, D'Agostini F, Balansky RM (2001) Mechanisms of $\mathrm{N}$-acetylcysteine in the prevention of DNA damage and cancer, with special reference to smoking-related end-points. Carcinogenesis 22: 999-1013.

19. Wang ZY, Zhou J, Luo L, Huang YL, Dong PD (2012) Predictive role of glutathione-S-transferase gene polymorphisms in the survival of gastric cancer cases. Asian Pac J Cancer Prev 13: 1515-1518.

20. Sharma R, Yang Y, Sharma A, Awasthi S, Awasthi YC (2004) Antioxidant role of glutathione S-transferases: protection against oxidant toxicity and regulation of stress-mediated apoptosis. Antioxid Redox Signal 6: 289-300.

21. Yan F, Yang WK, Li XY, Lin TT, Lun YN, et al. (2008) A trifunctional enzyme with glutathione S-transferase, glutathione peroxidase and superoxide dismutase activity. Biochim Biophys Acta 1780: 869-872.

22. YalÃßin O, KarataÅŸ F, ErulaÅŸ FA, Ozdemir E (2004) The levels of glutathione peroxidase, vitamin A, E, C and lipid peroxidation in patients with transitional cell carcinoma of the bladder. BJU Int 93: 863-866.

23. Jasim BT (2011) Determination the erythrocyte glutathione peroxidase activity and serum selenium level in patients with breast cancer. Tikrit Journal of Pure Science 16: 4-8.

24. Sreenivasa Rao CS, Sarala Kumari D (2012) Changes in plasma lipid peroxidation and the antioxidant system in women with breast cancer. IJBAS 1: 429-438.

25. Panis C, Victorino VJ, Herrera ACSA, Freitas LF, De Rossi T, et al. (2012) Differential oxidative status and immune characterization of the early and advanced stages of human breast cancer. Breast Cancer Res Treat 133: 881-888.

26. Srivastava DS, Mittal RD (2005) Free radical injury and antioxidant status in patients with benign prostate hyperplasia and prostate cancer. Indian J Clin Biochem 20: 162-165.

27. Ewadh MJ, Kadhum NH, Al Hamdani KJ, Alawad AS (2009) Relationship between antioxidants glutathione and total a-L-Fucose as a tumor markers in breast cancer patients. Medical Journal of Babylon 6: 164-174.

28. Townsend DM, Manevich Y, He L, Hutchens S, Pazoles CJ, et al. (2009) Novel role for glutathione S-transferase pi. Regulator of protein SGlutathionylation following oxidative and nitrosative stress. J Biol Chem 284: 436-445.

29. Su F, Hu X, Jia W, Gong C, Song E, et al. (2003) Glutathion S transferase pi indicates chemotherapy resistance in breast cancer. J Surg Res 113: 102-108.

30. Tsuchida S, Sekine Y, Shineha R, Nishihira T, Sato K (1989) Elevation of the placental glutathione S-transferase form (GST-pi) in tumor tissues and the levels in sera of patients with cancer. Cancer Res 49: 5225-5229.

31. Ewadh MJ, Kadhum NH, Al Hamdani KJ, Alawad AS (2009) The relationship between antioxidants glutathione, glutathione-s-transferase as tumor markers in breast cancer patients. Medical Journal of Babylon 6: 36-44.

32. Prabasheela B, Singh AK, Fathima A, Pragulbh K, Deka NJ, et al. (2011) Association between antioxidant enzymes and breast cancer. RRST 3: 93-95.

33. Sivakumar S, Devaraj N (2011) Enzymatic and non-enzymatic antioxidant status of breast cancer patients in Tamilnadu. IJPBS 2: 46-53.

34. Punnonen K, Ahotupa M, Asaishi K, Hyöty M, Kudo R, et al. (1994) Antioxidant enzyme activities and oxidative stress in human breast cancer. J Cancer Res Clin Oncol 120: 374-377.

35. Pawlowicz Z, Zachara BA, Trafikowska U, Maciag A, Marchaluk E, et al. (1991) Blood selenium concentrations and glutathione peroxidase activities in patients with breast cancer and with advanced gastrointestinal cancer. Journal of trace elements and electrolytes in health and disease 5: 275-277. 
Citation: Charushila YK and Subodhini AA (2015) Evaluation of Serum Antioxidants during Adjuvant Chemotherapy of Breast Cancer- A Prospective Observational Study. Biochem Anal Biochem 4: 171. doi:10.4172/2161-1009.1000171

Page 6 of 6

36. Moron MS, Depierre JW, Mannervik B (1979) Levels of glutathione glutathione reductase and glutathione S-transferase activities in rat lung and liver. Biochim Biophys Acta 582: 67-78.

37. Prabhu K, Bhat GP (2007) Serum total glutathione-s-transferase levels in oral cancer. J Cancer Res Ther 3: 167-168.

38. Paglia DE, Valentine WN (1967) Studies on the quantitative and qualitative characterization of erythrocyte glutathione peroxidase. J Lab Clin Med 70: 158-169.

39. Davis W Jr, Ronai Z, Tew KD (2001) Cellular thiols and reactive oxygen species in drug-induced apoptosis. J Pharmacol Exp Ther 296: 1-6.

40. De Rossi T, Panis C, Victorino VJ, Freitas de Freitas L, et al. (2009) Breast cancer and oxidative stress in chemotherapy. Applied Cancer Research 29: $1-6$
41. Czeczot H, Scibior D, Skrzycki M, Podsiad M, Porembska Z (2005) Glutathione level and activity of GSH dependent enzymes in gastric carcinoma patients-a preliminary report. Gastroenterol Pol 12: 107-111.

42. Mishra S, Sharma DC, Sharma P (2004) Studies of biochemical parameters in breast cancer with and without metastasis. Indian J Clin Biochem 19: 71-75.

43. Townsend DM, Tew KD (2003) The role of glutathione-S-transferase in anti-cancer drug resistance. Oncogene 22: 7369-7375.

44. Severini G (1993) Glutathione S-transferase activity in patients with cancer of the digestive tract. J Cancer Res Clin Oncol 120: 112-114.

45. Prabasheela B, Baskaran S (2014) Alteration of glutathione dependent enzymes in pre and post-operative breast carcinoma, JBMAS 1: 1-7. 